\title{
Sperm activation by heat shock protein 70 supports the migration of sperm released from sperm storage tubules in Japanese quail (Coturnix japonica)
}

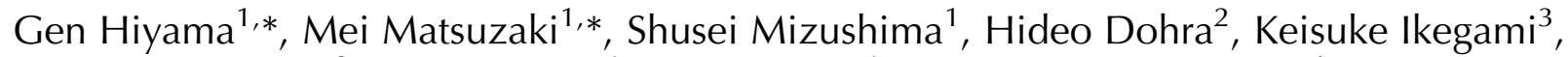 \\ Takashi Yoshimura ${ }^{3}$, Kogiku Shiba ${ }^{4}$, Kazuo Inaba $^{4}$ and Tomohiro Sasanami ${ }^{1}$ \\ ${ }^{1}$ Department of Applied Biological Chemistry, Faculty of Agriculture and ${ }^{2}$ Institute for Genetic Research and \\ Biotechnology, Shizuoka University, 836 Ohya, Shizuoka 422-8529, Japan, ${ }^{3}$ Graduate School of Bioagricultural \\ Sciences, Nagoya University, Furo-cho, Chikusa-ku, Nagoya 464-8601, Japan and ${ }^{4}$ Shimoda Marine Research Center, \\ University of Tsukuba, 5-10-1 Shimoda, Shizuoka 415-0025, Japan \\ Correspondence should be addressed to T Sasanami; Email: atsasan@ipc.shizuoka.ac.jp \\ *(G Hiyama and M Matsuzaki contributed equally to this work)
}

\begin{abstract}
Systems for maintaining the viability of ejaculated sperm in the female reproductive tract are widespread among vertebrates and invertebrates. In birds, this sperm storage function is performed by specialized simple tubular invaginations called sperm storage tubules (SSTs) in the uterovaginal junction (UVJ) of the oviduct. Although the incidence and physiological reasons for sperm storage in birds have been reported extensively, the mechanisms of sperm uptake by the SSTs, sperm maintenance within the SSTs, and control of sperm release from the SSTs are poorly understood. In this study, we demonstrated that the highly conserved heat shock protein 70 (HSP70) stimulates sperm motility in vitro and also that HSP70 expressed in the UVJ may facilitate the migration of sperm released from the SSTs. Quantitative RT-PCR analysis demonstrated that the expression of HSP70 mRNA in the UVJ increases before ovulation/oviposition. Gene-specific in situ hybridization and immunohistochemical analysis with a specific antibody to HSP70 demonstrated that HSP70 is localized in the surface epithelium of the UVJ. Furthermore, injection of anti-HSP70 antibody into the vagina significantly inhibited fertilization in vivo. In addition, we found that recombinant HSP70 activates flagellar movement in the sperm and that the binding of recombinant HSP70 to the sperm surface is mediated through an interaction with voltage-dependent anion channel protein 2 (VDAC2). Our results suggest that HSP70 binds to the sperm surface by interacting with VDAC2 and activating sperm motility. This binding appears to play an important role in sperm migration within the oviduct.
\end{abstract}

Reproduction (2014) 147 167-178

\section{Introduction}

The ability to store sperm in the female reproductive tract is widespread among insects, fish, amphibians, reptiles, birds, and mammals (Birkhead \& Mфller 1993, Holt \& Lloyd 2010, Holt 2011). The females of these taxa employ a variety of specialized structures in their genital tracts to store sperm, including sperm reservoirs in mammals (Suarez 2010), spermathecae in amphibians (Kuehnel \& Kupfer 2012), and spermathecae and seminal receptacles in insects (Wolfner 2011). These structures store the sperm until ovulation or until the ovum is transported to the site of fertilization. Birds employ specialized simple tubular invaginations, referred to as sperm storage tubules (SSTs), which are found in the oviduct (Bobr et al. 1964, Shindler et al. 1967, Frieß et al. 1978, Brillard 1993). In domestic birds, such as chickens, turkeys, quail, and ducks, these SSTs can store sperm that have entered the female reproductive tract for 2-15 weeks; in other bird species, sperm can be stored for varying periods (Bakst et al. 1994, Bakst 2011). This extended viability of avian sperm contrasts markedly with the relatively short lifespan of mammalian sperm, which remain viable only for a few days, though the phenomenon of sperm storage had been demonstrated in some species of bats (Roy \& Krishna 2010).

Although the SSTs of birds are located in the lamina propria of the mucosal folds in the uterovaginal junction (UVJ) and in the infundibulum, the primary site of sperm storage is the SSTs in the UVJ (Burke \& Ogasawara 1969, Brillard 1993). The spermatozoa are transported to the infundibulum, which is the site of fertilization and which also serves as a secondary sperm storage site (Shindler et al. 1967, Bakst 1981). The precise mechanism of sperm storage in the avian oviduct has not been fully 
resolved since its discovery in the 1960s, primarily because direct observation of sperm movements in the oviduct is difficult due to the thickness and opacity of the oviduct wall. In addition, the isolation and analysis of fluids in the SST lumen that may be involved in sperm maintenance are difficult due to the small luminal diameter of the SSTs $(\sim 10-20 \mu \mathrm{m})$ and location of the SSTs (i.e. embedded in the UVJ mucosa). As a result, only indirect methods, such as counting of the sperm recovered from different oviduct sections after insemination or determination of the sperm filling rate of the SSTs, can be used to elucidate the mechanism of sperm storage and sperm migration in the oviduct (Burke \& Ogasawara 1969, Compton et al. 1978, Brillard 1993). We have previously employed similar techniques to show that the release of sperm from the SSTs is a regulated event during the ovulatory cycle and that progesterone acts as a sperm-release factor in birds (Ito et al. 2011). Our observations indicated that the sperm release from the SSTs is orchestrated with ovulation by the stimulation of progesterone to increase the chance of fertilization. Nonetheless, our knowledge of the mechanism of related events including sperm uptake by the SSTs, sperm maintenance within the SSTs, and control of sperm release from the SSTs remains insufficient.

Recently, Holt et al. have reported that the soluble fraction of the oviductal apical plasma membrane (sAPMs) can both reduce sperm motility and enhance sperm viability in pigs (Satake et al. 2006). The same research group has found that heat shock $70 \mathrm{kDa}$ protein 8 (HSPA8), also referred to as Hsc70 or Hsp73, is present in the SAPMs and that recombinant HSPA8 exerts similar effects on sperm (Elliott et al. 2009). The HSP70 family contains multiple homologs, ranging in size from 66 to $78 \mathrm{kDa}$; these homologs are the eukaryotic equivalents of bacterial DnaK (Duagaard et al. 2007). Members of the HSP70 family are characterized by the presence of highly conserved $\mathrm{N}$-terminal ATPase and C-terminal protein-binding domains. The binding of peptides to HSP70 stimulates the inherent ATPase activity of HSP70 and facilitates ATP hydrolysis and enhanced peptide binding (Duagaard et al. 2007). Nucleotide exchange and substrate binding by HSP70 coordinate the folding of newly synthesized proteins, refolding of misfolded or denatured proteins, trafficking of proteins across cell membranes, inhibition of protein aggregation, and targeting of protein degradation via the proteasomal pathway in the cells (Duagaard et al. 2007). Our preliminary proteomic analyses have shown that the soluble extracts of UVJ mucosa contain HSP70, but we do not know whether HSP70 plays a role in sperm storage or sperm migration in the oviduct of birds. In this report, we present the first evidence demonstrating that HSP70 stimulates sperm motility in vitro and that HSP70 expressed in the UVJ might support the migration of sperm that are released from the SSTs in Japanese quail.

\section{Materials and methods}

\section{Animals and tissue preparation}

Male and female Japanese quail, Coturnix japonica, 8-20 weeks of age (Motoki Corporation, Tokorozawa, Japan), were maintained individually under a photoperiod of $14 \mathrm{~h}$ light: $10 \mathrm{~h}$ darkness (with the light on at $0500 \mathrm{~h}$ ) and provided with water and a commercial diet (Motoki Corporation) ad libitum. The time of oviposition in each bird was recorded every day to estimate the time of ovulation (ovulation occurs $\sim 30$ min after oviposition; Etches \& Schoch 1984). We selected birds that regularly laid eggs. Females were decapitated 8, 14, 20, or $25 \mathrm{~h}$ after oviposition, and the funnel part of the infundibulum or the mid-portion of the magnum, isthmus, uterus, or vagina was dissected ( $\sim 0.1 \mathrm{~g}$ wet weight each). The UVJ mucosa around the junction of the uterus and vagina was dissected and placed in physiological saline. The UVJS containing the SSTs were identified by stereomicroscopy and isolated with forceps and scissors under a stereomicroscope according to the method of Ito et al. (2011). All the experimental procedures for the care and use of animals in the present study were approved by the Animal Care Committee of Shizuoka University (approval number: 24-12).

\section{Real-time PCR analysis}

Total RNA was isolated from the dissected tissue samples using RNAiso (Takara Biomedical, Otsu, Japan) according to the manufacturer's instructions. Aliquots $(0.5 \mu \mathrm{g})$ were reversetranscribed at $37{ }^{\circ} \mathrm{C}$ for 15 min using the ReverTra Ace qPCR Kit (Toyobo, Osaka, Japan). The reaction product was subjected to real-time PCR according to the instructions provided for the use of the Light Cycler Nano System with the FastStart Essential DNA Green Master (Roche Applied Science). Briefly, following a denaturing step at $95{ }^{\circ} \mathrm{C}$ for $10 \mathrm{~s}$, PCR was carried out using a thermal protocol consisting of $95{ }^{\circ} \mathrm{C}$ for $20 \mathrm{~s}, 55.4{ }^{\circ} \mathrm{C}$ for $20 \mathrm{~s}$, and $72{ }^{\circ} \mathrm{C}$ for $20 \mathrm{~s}$ in $20 \mu \mathrm{l}$ buffer containing $0.2 \mu \mathrm{M}$ of each primer. The sense and antisense primers used for the amplification of HSP7O were 5'-GCTATTGCCTATGGCTTGGA-3' and 5'-CAGCTGTGGACTTCACCTCA-3' respectively (GenBank accession number: EU622852). For the normalization of data, we amplified the $S 17$ gene (GenBank accession number: AY232491, sense primer: 5'-CCAGACACCAAGGAGATGCT-3' and AY232491, antisense primer: 5'-GCCTCGTGGTGTTTTGAAGT-3') using the cycling conditions followed for the amplification of HSP70. To normalize the data, $\Delta C T$ was calculated for each sample by subtracting the $C T$ value of $S 17$ from the $C T$ value of HSP70. For relative quantification, $\Delta C T$ of the defined control group was subtracted from the $\Delta C T$ of each experimental sample to generate $\Delta \Delta C T$. The $\Delta \Delta C T$ values were then used to calculate the approximate fold difference, $2^{-\Delta \Delta C T}$. The results are expressed as the HSP7O mRNA:S17 mRNA ratio.

\section{Production of anti-HSP7O antiserum}

Rabbit polyclonal anti-HSP70 antiserum was raised against bacterially expressed His-tagged HSP70 (from Met ${ }^{1}$ to Asp ${ }^{634}$ ). Quail HSP70 cDNA was amplified by PCR (cycling conditions: 
$94{ }^{\circ} \mathrm{C}$ for $1 \mathrm{~min}, 62{ }^{\circ} \mathrm{C}$ for $1 \mathrm{~min}$, and $72{ }^{\circ} \mathrm{C}$ for $2 \mathrm{~min}$ for 30 cycles) to introduce BamHI and Sall sites upstream of Met $^{1}$ and downstream of $\mathrm{Asp}^{634}$ respectively. The sense and antisense primers used were 5'-GAGGGATCCATGTCAGGCAAAGGGCCGGC- $3^{\prime}$ and $5^{\prime}$-CAGGTCGACATCTACTTCTTCAATGGTTG-3' respectively. The PCR product containing the HSP7O CDNA was digested with BamHI and Sall and ligated into a pCold TF DNA vector (Takara Biomedical) treated with the same restriction enzymes. The resulting construct was transformed into competent Escherichia coli, strain BL21 (Takara Biomedical), and an ampicillin-resistant clone was selected after the nucleotide sequence analysis was carried out. Recombinant HSP70 or tag protein alone was expressed in the presence of $1 \mathrm{mM}$ isopropyl- $\beta$-thiogalactopyranoside at $15{ }^{\circ} \mathrm{C}$ for $24 \mathrm{~h}$, and the protein was purified from the cell lysate using nickel resin (Novagen, Madison, WI, USA) according to the manufacturer's instructions. The purity of the recombinant HSP70 or tag protein was verified by SDS-PAGE followed by Coomassie Brilliant Blue (CBB) staining.

A single female New Zealand White rabbit (SLC, Hamamatsu, Japan) was immunized with the recombinant HSP70 as described previously (Kuroki \& Mori 1997). Briefly, the rabbit was injected s.c. at multiple sites along the back with $1 \mathrm{ml}$ of an emulsion prepared by mixing equal volumes of Freund's complete adjuvant (Sigma-Aldrich) and recombinant HSP70 $(300 \mu \mathrm{g} / \mathrm{ml})$. Booster injections with the same amount of antigen in Freund's incomplete adjuvant (Sigma-Aldrich) were administered 6 and 8 weeks after the first immunization. Blood was collected two weeks after the final injection, and serum aliquots were stored at $4{ }^{\circ} \mathrm{C}$.

\section{Effects of intravaginal injection of anti-HSP7O antibody}

IgG of anti-HSP70 antiserum or normal rabbit serum was purified with rProtein A Fast Flow media (GE Healthcare, Little Chalfont, UK) according to the manufacturer's instructions. The recovered IgG was extensively dialyzed against PBS and diluted at a concentration of $2 \mathrm{mg} / \mathrm{ml}$ with PBS. IgG was intravaginally injected $(50 \mu \mathrm{l} / \mathrm{bird}, n=6)$ in the morning and evening (evening corresponds to the time after oviposition). The females were housed with males the next morning (one female with two males) and allowed to copulate for $8 \mathrm{~h}$. Oviposited eggs were collected every day, and the presence or absence of fertilization was determined visually by confirming the presence of an area pellucida and/or area opaca in the blastoderm without additional incubation.

\section{Gel electrophoresis and western blotting}

UVJ mucosa $(\sim 0.1 \mathrm{~g})$ isolated from two birds $8,14,20$, or $25 \mathrm{~h}$ after oviposition was minced in $0.2 \mathrm{ml}$ ice-cold PBS supplemented with $0.1 \mathrm{mmol} / \mathrm{l}$ phenylmethylsulfonyl fluoride (PMSF; Sigma-Aldrich), $40 \mu \mathrm{g} / \mathrm{ml}$ bestatin (Sigma-Aldrich), $0.5 \mu \mathrm{g} / \mathrm{ml}$ leupeptin (Sigma-Aldrich), and $10 \mu \mathrm{g} / \mathrm{ml}$ soybean trypsin inhibitor (Sigma-Aldrich) and extracted on ice for $3 \mathrm{~h}$ with occasional vortexing. Debris were removed by centrifugation at $800 \mathrm{~g}$ for $5 \mathrm{~min}$, and the supernatants were centrifuged at $20000 \mathrm{~g}$ for $10 \mathrm{~min}$ at $4{ }^{\circ} \mathrm{C}$. The supernatants were used as
UVJ extracts. The protein concentration of the samples was determined using a BCA Protein Assay kit (Pierce, Rockford, IL, USA).

SDS-PAGE was carried out under reducing conditions as described previously (Laemmli 1970), using 12\% (w/v) and 5\% $(\mathrm{w} / \mathrm{v})$ polyacrylamide for the resolving and stacking gels respectively. For western blotting, proteins separated by SDSPAGE were transferred onto a PVDF membrane (Immobilon-P, Millipore, Bedford, MA, USA; Matsudaira 1987). The membrane was then incubated with a blocking buffer containing $5 \%$ $(\mathrm{w} / \mathrm{v})$ skimmed milk in PBS supplemented with $0.1 \%(\mathrm{w} / \mathrm{v})$ Tween 20 for $30 \mathrm{~min}$. The membrane was allowed to react with anti-HSP70 antiserum (1:1000) or anti-HSP70 antiserum preincubated with antigen proteins (1:1000) diluted with a blocking buffer (Sasanami et al. 2002) and visualized using a chemiluminescence technique (Amersham Pharmacia Biotech) using HRP-conjugated anti-rabbit IgG (Cappel, Durham, NC, USA). Chemiluminescence was detected using ImageQuant LAS 500 (GE Healthcare). Visualized blots were digitized using a Macintosh Image Analysis System (ImageJ, v. 1.440, http:// imagej.nih.gov/ij).

\section{Semen collection and preparation}

Semen was obtained from male quail during mating before ejaculation according to the procedure of Kuroki \& Mori (1997). Semen obtained from two to three males was suspended in a sperm extender $(136 \mathrm{mmol} / \mathrm{l} \mathrm{NaCl}, 5.4 \mathrm{mmol} / \mathrm{l} \mathrm{KCl}$, $0.8 \mathrm{mmol} / \mathrm{l} \mathrm{MgSO}, 1.26 \mathrm{mmol} / \mathrm{I} \mathrm{CaCl}_{2}, 4.2 \mathrm{mmol} / \mathrm{l} \mathrm{NaHCO}_{3}$, and $5.6 \mathrm{mmol} / \mathrm{l}$ glucose buffered at $\mathrm{pH} 7.4$ with $10 \mathrm{mmol} / \mathrm{l} \mathrm{HEPES})$. The concentrations of sperm were measured with a hemocytometer, and sperm viability was assessed using a LIVE/DEAD sperm viability kit according to the manufacturer's instructions (Molecular Probes, Eugene, OR, USA). Sperm were incubated at $39^{\circ} \mathrm{C}$ in all the experiments.

To obtain sperm plasma membrane lysate (SPML), the ejaculates were washed three times with ice-cold PBS with repeated centrifugation at $800 \mathrm{~g}$ for $3 \mathrm{~min}$ at $4{ }^{\circ} \mathrm{C}$, and the final pellet was suspended in a cavitation buffer containing $150 \mathrm{mmol} / \mathrm{l} \mathrm{NaCl}$ and $20 \mathrm{mmol} / \mathrm{l}$ HEPES $(\mathrm{pH} \mathrm{7.4)}$. The suspension was cavitated with a cell disruptor (Parr Instrument Company, Moline, IL, USA) at 400 psig, and the cell debris were removed by centrifugation at $10000 \mathrm{~g}$ for $10 \mathrm{~min}$. The supernatants were further centrifuged at $158000 \mathrm{~g}$ for $30 \mathrm{~min}$, and the precipitates were suspended in a cavitation buffer containing $0.1 \%$ (w/v) Triton X-100, $0.1 \mathrm{mmol} / \mathrm{I}$ PMSF, $0.5 \mu \mathrm{g} / \mathrm{ml}$ leupeptin, and $10 \mu \mathrm{g} / \mathrm{ml}$ soybean trypsin inhibitor. After determining the protein concentration, the suspensions were mixed with Laemmli sample preparation buffer (Laemmli 1970) and used as SPML. The SPML samples were stored at $-80{ }^{\circ} \mathrm{C}$ for far-western blotting.

\section{Far-western blotting}

For far-western blotting, the SPML (5 $\mu \mathrm{g} /$ lane) samples separated by SDS-PAGE were electrotransferred onto a PVDF membrane as described above. The strips were blocked with N101 blocker (NOF Corporation, Tokyo, Japan) for 30 min with shaking, rinsed with PBS, and incubated with or without 
recombinant HSP70 $(0.1 \mu \mathrm{g} / \mathrm{ml})$ for $30 \mathrm{~min}$ at room temperature. After incubation, the strips were washed with PBS and blocked again with the same blocker. After rinsing with PBS, the HSP70 bound to the membrane was visualized using the procedure employed for western blotting. After detection, the PVDF membrane was washed three times with PBS and stained with CBB. After staining, the image visualized by CBB was merged with the chemiluminescent image by means of imaging software (ImageQuant, GE Healthcare) to identify the band that interacted with HSP70.

\section{Detection of bound HSP70 on sperm surface}

Ejaculated sperm isolated from two to three males were suspended in the semen extender described above and washed three times with repeated centrifugation at $800 \mathrm{~g}$ for $3 \mathrm{~min}$. The washed sperm were then incubated with a semen extender containing $30 \mu \mathrm{g} / \mathrm{ml}$ recombinant HSP70 for $30 \mathrm{~min}$. After washing with three times with sperm extender, sperm were fixed in formaldehyde (final concentration $3.7 \%(\mathrm{v} / \mathrm{v})$ ) for $10 \mathrm{~min}$ at room temperature. After air-drying, the slides were washed with PBS for $5 \mathrm{~min}$, and the cells were incubated with PBS containing 1\% BSA and 10\% normal goat serum for $1 \mathrm{~h}$ for blocking. The cells were then incubated with anti-HSP70 serum $(1: 100)$ or anti-HSP70 serum preincubated with antigen proteins $(1: 100)$ for $2 \mathrm{~h}$ at $4{ }^{\circ} \mathrm{C}$. After washing with PBS, they were incubated with Texas Red-conjugated sheep anti-rabbit IgG (1:200, Cappel) for $1 \mathrm{~h}$ at $4{ }^{\circ} \mathrm{C}$. After washing with PBS, they were embedded in glycerol and examined under a fluorescence microscope equipped with an interferencecontrast apparatus with a $40 \times$ objective (BX51, Olympus Optics, Tokyo, Japan).

\section{LC-tandem mass spectrometry analysis}

The SDS-PAGE gel strip containing the SPML $(20 \mu \mathrm{g})$ was stained with CBB. The piece of gel $\left(\sim 1 \mathrm{~mm}^{2}\right)$ containing the HSP70-binding protein identified as described above was excised. The proteins in the gel were processed for in-gel digestion using sequence-grade trypsin as suggested by the manufacturer (Promega Corporation). The peptides recovered from the gel were analyzed by tandem mass spectrometry (MS/MS; NanoFrontier eLD, Hitachi High-Technologies Corporation) according to the manufacturer's instructions. To identify the protein(s) obtained from the MS/MS analysis, a de novo sequencing software package, PEAKS, was used as described previously (Ma et al. 2003). To confirm the reliability of the de novo sequencing data, we used two other proprietary identification programs, Mascot (http://www.matrixscience. com/) and SPIDER (http://www.bioinfor.com/products/peaks/ spider.php), as described previously (Perkins et al. 1999).

\section{Sperm motility analysis and intracellular $\mathrm{Ca}^{2+}$ imaging}

The ejaculated sperm were incubated with a sperm extender containing $30 \mu \mathrm{g} / \mathrm{ml}$ recombinant HSP70 or $10 \mu \mathrm{mol} / \mathrm{l}$ erastin. Erastin is an anti-tumor agent that binds to voltage-dependent anion channels (VDACs), more specifically to VDAC2, and alters their gating (Yagoda et al. 2007, Simamura et al. 2008).
The concentration of erastin used in the present study was adopted from Yagoda et al. (2007). An appropriate vehicle (DMSO for erastin and PBS for HSP70) was included in the incubation mixture for the control experiments. Motility was evaluated by observing the sperm in several areas of the petri dish directly using a stereomicrosope, and their motility was scored on the 0-5 system of Wheeler \& Andrews (1943). The movements of the sperm and waveforms of flagellar beats were observed using a phase-contrast microscope (BX51; Olympus Optics) with a $20 \times$ objective and recorded with a high-speed CCD camera (HAS-220; Ditect, Tokyo, Japan). Images were captured using a frame rate of 200 frames per second ( $f p s)$. The linear velocities of the sperm and the amplitudes of the flagella were analyzed using the Bohboh Software (Bohboh Soft, Tokyo, Japan). Briefly, the flagellar movements of the sperm were recorded by a high-speed camera, and ten images taken at every $1 / 20 \mathrm{~s}$ were overlaid. The linear velocities of the sperm $(\mu \mathrm{m} / \mathrm{s})$ and the maximum amplitudes of flagellar bending $(\mu \mathrm{m})$ were calculated from the overlaying images using the Bohboh Software.

For $\mathrm{Ca}^{2+}$-imaging analysis, the ejaculated sperm $\left(2 \times 10^{7}\right.$ cells $\left./ \mathrm{ml}\right)$ were incubated with $1 \mu \mathrm{mol} / /$ Fluo- $8 \mathrm{H} \mathrm{AM}$, a fluorescent calcium indicator (Nacalai Tesque, Kyoto, Japan), for $10 \mathrm{~min}$ at $39{ }^{\circ} \mathrm{C}$. After incubation, the sperm suspension was added to the sperm extender that was supplemented with or without recombinant $\mathrm{HSP} 70(30 \mu \mathrm{g} / \mathrm{ml})$ or tag protein $(30 \mu \mathrm{g} / \mathrm{ml})$ and incubated for an additional $30 \mathrm{~min}$. For the control experiment, Fluo-8H AM-loaded sperm were incubated in the extender containing only a vehicle (PBS). $\mathrm{Ca}^{2+}$ imaging was carried out as described previously (Mizuno et al. 2012) using an Olympus filter set (excitation filter, BP490-500; dichromatic mirror, DM505; and emission filter, BA510-550) with a $40 \times$ objective and recorded on a personal computer connected to a digital CCD camera (ImagEM, C9100-13; Hamamatsu Photonics, Hamamatsu, Japan) at $50 \mathrm{fps}$ using the imaging application Aquacosmos (Hamamatsu Photonics). The maximum fluorescent intensity of flagella from ten randomly selected spermatozoa after subtraction of a background value was quantified using ImageJ (v. 1.440, http://imagej.nih.gov/ij). The measurement was performed at least at five points in one sperm. The experiment was repeated six times.

\section{ATP assay}

For the measurements of intracellular ATP levels, the ejaculated sperm $\left(2 \times 10^{7}\right.$ cells $\left./ \mathrm{ml}\right)$ were incubated with or without recombinant HSP70 $(30 \mu \mathrm{g} / \mathrm{ml})$ for 10 or $30 \mathrm{~min}$ before centrifugation at $800 \mathrm{~g}$ for $3 \mathrm{~min}$. After washing with a sperm extender, the sperm pellet was dissolved in ATP assay reagent ('Cellno' ATP Assay Reagent, TOYO B-Net Co., Tokyo, Japan), and the fluorescent signal was measured using ImageQuant LAS 500 (GE Healthcare).

\section{In situ hybridization}

The birds were decapitated, the UVJ was removed, and frozen sections were prepared for in situ hybridization, which was carried out as described previously (Yoshimura et al. 2000). The antisense 45 mer oligonucleotide probes for HSP7O 
(5'-ACGTTTCAAGAATGGTCACCACGCAGCAACAGGCAGCAACAGGGC-3' , 5'-GCACCACGTATTCCTGTGTGGGTGTCTTCCAGCATGGCAAAGTGG-3' , $^{\prime}$-CTGAACGTCAGTGCCGTGGACAAGAGTACAGGAAAGGAGAACAAG-3', and 5'-CACCTCCATCACTCGTGCCCGCTTTGAGGAGCTCAATGCTGATCT- $3^{\prime}$ ) were labeled with $\left[{ }^{33} \mathrm{P}\right]$ dATP (NEN Life Science Products, Boston, MA, USA) using terminal deoxyribonucleotidyl transferase (Gibco). The probes were then mixed in equal amounts and used for hybridization. The sense probe was also labeled as described above, and hybridization was carried out overnight at $42{ }^{\circ} \mathrm{C}$. The slides were washed two times at room temperature for $30 \mathrm{~min}$ and at $55^{\circ} \mathrm{C}$ for $40 \mathrm{~min}$. After washing, the slides were coated with Kodak NTB-2 emulsion (Kodak) and exposed for 7 days at $4{ }^{\circ} \mathrm{C}$ in a dark box. After exposure, the slides were developed in Kodak Dektol and mounted in water. The specimens were examined under a microscope equipped with an interference-contrast apparatus (BX51, Olympus Optics).

\section{Immunohistochemistry}

To detect HSP70 protein in the UVJ, UVJ mucosa was fixed in Bouin's fixative and embedded in Paraplast (Oxford Labware, St. Louis, MO, USA). The sections (4 $\mu \mathrm{m}$ thickness) were air-dried and then incubated with ethanol containing $1 \% \mathrm{H}_{2} \mathrm{O}_{2}$ for $20 \mathrm{~min}$ to inactivate endogenous peroxidase after deparaffinization. After washing with PBS, the sections were blocked with PBS containing 1\% BSA and $10 \%$ normal goat serum for $1 \mathrm{~h}$. In immunohistochemical techniques, which were the same as those described previously (Sasanami et al. 2002), anti-HSP70 antiserum (1:100) or anti-HSP70 antiserum preincubated with antigen proteins $(1: 100)$ and HRP-conjugated goat anti-rabbit lgG (Cappel) was used. The samples were lightly stained with hematoxylin. The immunolabeled sections were examined under a light microscope (BX51, Olympus Optics) using a Nomarski filter.

\section{Statistical analysis}

Data are expressed as means \pm s.D. and were analyzed for significant differences by ANOVA. Means were compared using Tukey's test. For percentage data, an arcsine square-root transformation was performed, and the transformed data were compared using Student's t-test. Comparisons of the motility scores of groups were made using the Mann-Whitney $U$ test. Differences were considered statistically significant when $P<0.05$.

\section{Results}

\section{Expression of HSP70 is regulated during the ovulatory cycle}

As shown in Fig. 1A, the levels of HSP7O mRNA were high in the infundibulum, UVJ, and vagina and low in the magnum, isthmus, and uterus. We also examined changes in the abundance of $H S P 70$ transcripts during the ovulatory cycle in the UVJ $(n=3$; Fig. 1B) and found that the expression levels of HSP7O increased
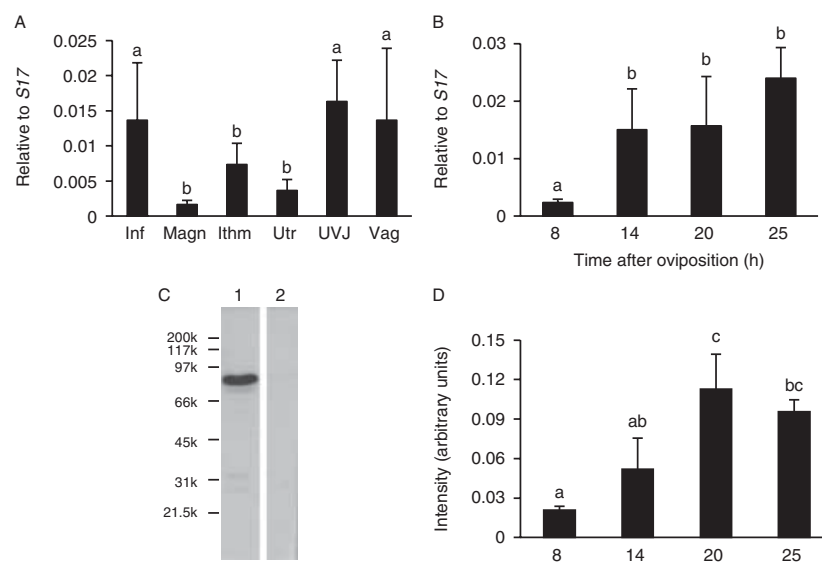

$$
\text { D }
$$

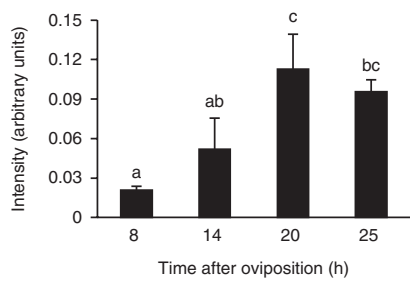

Figure 1 Expression of HSP70 in the oviduct. (A) Total RNA extracted from the infundibulum (Inf), magnum (Magn), isthmus (Ithm), uterus (Utr), UVJ, or vagina (Vag) was reverse-transcribed with a random primer, and aliquots were used in real-time PCR. Data were normalized to those obtained for $S 17$ and are expressed as means \pm s.D. of three independent experiments. (B) The UVJ isolated from the female birds 8, 14,20 , or $25 \mathrm{~h}$ after oviposition was processed for real-time PCR analysis using HSP70 primers. Data were normalized to those obtained for $S 17$ and are expressed as means \pm s.D. of three independent experiments. Values with different letters are significantly different $(P<0.05)$. (C) The UVJ extracts $(10 \mu \mathrm{g}$ protein/lane) were separated by SDS-PAGE under reducing conditions, transblotted onto a PVDF membrane, and detected with anti-HSP70 antiserum (lane $1 ; 1: 1000$ ) or anti-HSP70 antiserum preabsorbed with antigen proteins (lane 2; 1:1000). (D) The UVJ isolated from the female birds 8, 14, 20, or $25 \mathrm{~h}$ after oviposition was extracted and subjected to western blotting using anti-HSP70 antiserum. Band intensities were quantified and are expressed as means \pm s.D. of three independent experiments. Values with different letters are significantly different $(P<0.05)$.

dramatically $8-14 \mathrm{~h}$ after oviposition in the UVJ, with levels remaining high until $25 \mathrm{~h}$ after oviposition.

Western blotting demonstrated that the anti-HSP70 antiserum reacted strongly with a $70 \mathrm{kDa}$ band in the UVJ extracts under reducing conditions (Fig. 1C, lane 1). Conversely, no band was detected when the blot was allowed to react with anti-HSP70 antiserum preincubated with antigen proteins (Fig. 1C, lane 2), suggesting that our anti-HSP70 antiserum specifically binds to $70 \mathrm{kDa}$ quail HSP70 proteins. We also determined the expression levels of HSP70 protein during the ovulatory cycle (Fig. 1D). In accordance with the mRNA expression pattern observed during the ovulatory cycle, the intensity of the HSP70 band was low $8 \mathrm{~h}$ after oviposition. It increased $14 \mathrm{~h}$ after oviposition and was markedly higher 20 and $25 \mathrm{~h}$ after oviposition.

In situ hybridization revealed intense signals on the surface epithelium of the UVJ (Fig. 2A, arrowheads) when the specimens were hybridized with an antisense probe, suggesting that the $H S P 70$ mRNA is transcribed in the UVJ. Although the signal was very weak, silver grains indicating the presence of mRNA were observed in the epithelial cells of the SSTs (arrows in Fig. 2A). 

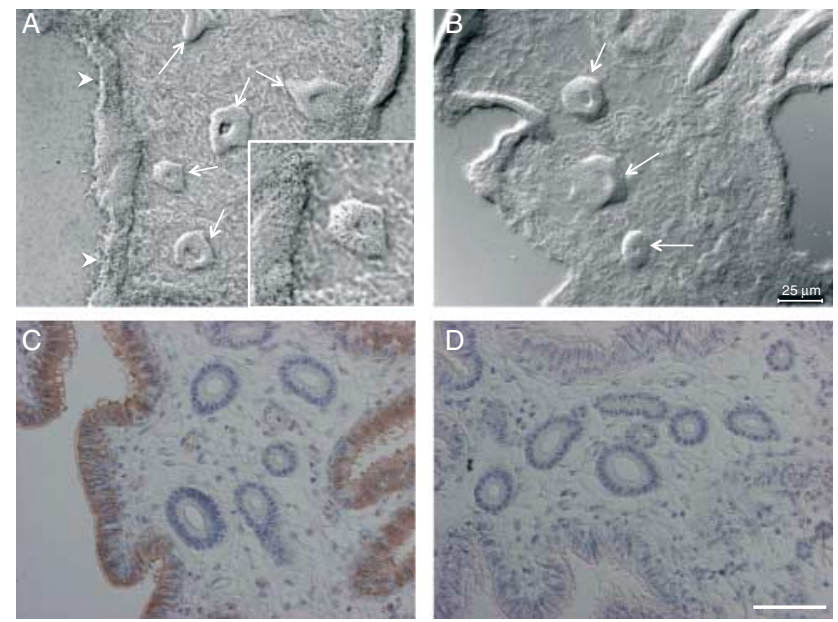

Figure 2 Localization of HSP70 in the UVJ. Autoradiograms of the UVJ sections after hybridization with a ${ }^{33} \mathrm{P}$-labeled antisense probe specific for $\operatorname{HSP7O}(\mathrm{A})$ or sense probe (B) are shown. Inset in (A) shows the enlarged view of the hybridization site in (A). Arrowheads and arrows in (A and B) indicate the surface epithelium of the UVJ and the SST respectively. Representative results of two experiments are shown $(n=2)$. Bar $=25 \mu \mathrm{m}$. Immunohistochemical observations using antiHSP70 antiserum (C) or anti-HSP70 antiserum preabsorbed with antigen proteins (D). Nuclei were counterstained with hematoxylin. Representative results of three experiments are shown. Bar $=50 \mu \mathrm{m}$.

These radiolabeled signals were not observed in specimens that had been hybridized with the sense probe (Fig. 2B). Immunohistochemical analysis revealed that immunoreactive HSP70 proteins were mainly localized in the surface epithelium of the UVJ (Fig. 2C). Positive signals were not detected in the epithelial cells of the SSTs. No such intense signals were observed when the specimens were incubated with anti-HSP70 antiserum preincubated with antigen proteins (Fig. 2D).

\section{Effect of HSP7O on sperm motility in vitro}

We first injected anti-HSP70 antibody into the vagina and then examined the fertility of birds after natural mating. When birds $(n=6)$ were treated with nonspecific rabbit IgG, fertility was $>70 \%$; however, fertility decreased to $<10 \%$ when the birds were injected with anti-HSP70 antibody (Fig. 3A). Conversely, the antiHSP70 antibody did not affect sperm uptake by the SSTs because, as in the case of normal IgG-treated birds (Fig. 3B), sperm were observed in the SSTs of the antiHSP70 antibody-treated birds (Fig. 3C). The percentage of SSTs in the IgG-treated birds containing sperm $24 \mathrm{~h}$ after mating was $33.3 \pm 17.4 \% \quad(n=4$, mean \pm s.D. $)$, which was not markedly different from that observed in the anti-HSP70 antibody-treated birds (27.6 $\pm 7.3 \%$; $n=4$, mean \pm s.D.). These results indicate that the antiHSP70 antibody interferes neither with sperm transport to the UVJ nor with sperm entrance into the SSTs, but that it might affect sperm migration from the SSTs to the site of fertilization.
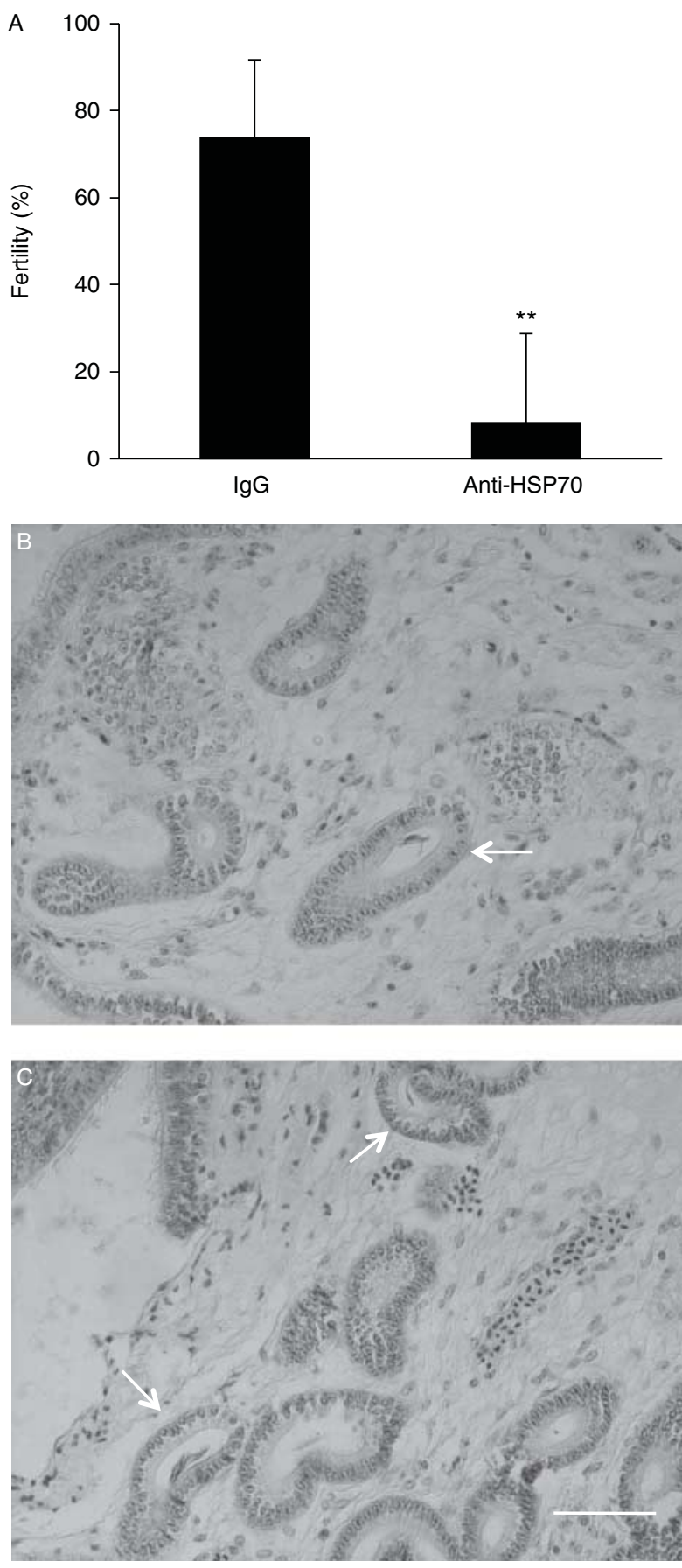

Figure 3 Effect of intravaginal injection of anti-HSP70 antibody on fertilization in Japanese quail. (A) Female birds injected with nonspecific rabbit $\operatorname{lgG}(2 \mathrm{mg} / \mathrm{ml}, 50 \mu \mathrm{l})$ or anti-HSP70 antibody $(2 \mathrm{mg} / \mathrm{ml}, 50 \mu \mathrm{l})$ were mated, and the oviposited eggs were collected daily for 7 days. The eggs were cracked to observe whether embryo development had occurred to confirm fertilization. Fertility was calculated and is expressed as means \pm s.D. Six birds were injected within each treatment group. Asterisks indicate a significant difference, $P<0.001$. (B and C) UVJ mucosa of the IgG-injected (B) or anti-HSP70 antibody-injected (C) birds was processed for histochemical observation by hematoxylin-eosin staining. Arrows in (B and C) indicate SSTs with sperm in the lumen. Representative results of three experiments are shown. Bar $=50 \mu \mathrm{m}$. 

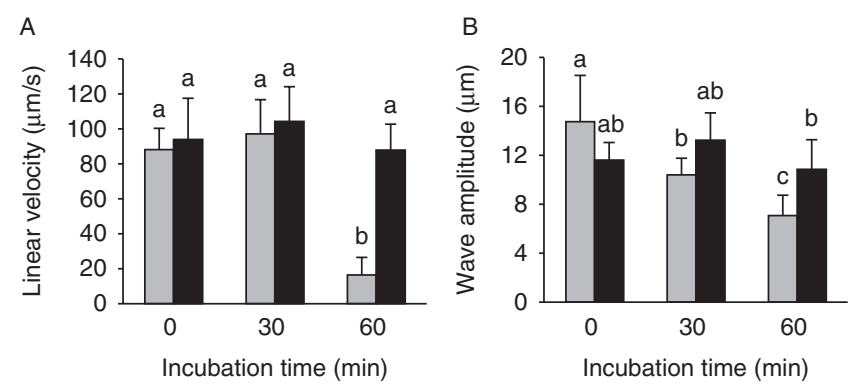

C
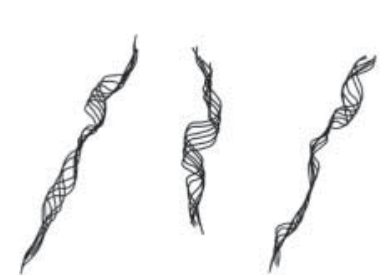

D
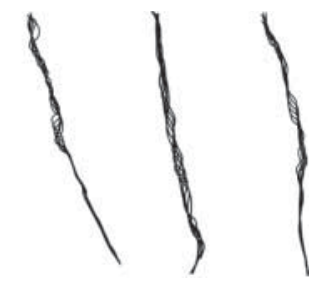

Figure 4 Activation of sperm motility by HSP70 in vitro. (A and B) Linear velocity of the sperm $(\mathrm{A})$ and maximum amplitude of flagellar bending (B) during incubation $(0,30$, or $60 \mathrm{~min})$ in the presence of tag protein (gray bars, $30 \mu \mathrm{g} / \mathrm{ml}$ ) or recombinant HSP70 (black bars, $30 \mu \mathrm{g} / \mathrm{ml}$ ) were measured. Data are expressed as means \pm s.D. of three independent experiments with ten sperm. Values with different letters are significantly different $(P<0.05)$. (C and D) Sperm flagellar bending patterns at 30 min of incubation in the presence of recombinant HSP70 $(C, 30 \mu \mathrm{g} / \mathrm{ml})$ or tag protein (D, $30 \mu \mathrm{g} / \mathrm{ml}$ ). Trajectories of three representative sperm for $1 / 40 \mathrm{~s}$ are shown.

These findings prompted us to examine whether HSP70 affects sperm motility directly. To confirm this hypothesis, we incubated the ejaculated sperm with recombinant HSP70 in vitro. After 60 min of incubation in the presence of recombinant HSP70 or tag protein alone, the motility score of the HSP70 group was significantly higher than that of the tag protein group $(n=9, P$ value $=0.015)$. The linear velocity of sperm incubated with the tag protein alone remained high $(\sim 80 \mu \mathrm{m} / \mathrm{s})$ for $30 \mathrm{~min}$ of incubation, before decreasing significantly at $60 \mathrm{~min}$ (Fig. 4A, gray bars). Conversely, in the presence of recombinant HSP70, the linear velocity of sperm remained equivalent to that at the start of incubation, even after $60 \mathrm{~min}$ (Fig. 4A, solid bars). In the absence of recombinant HSP70, wave amplitude decreased gradually, but significantly, reaching approximately half that at the start after $60 \mathrm{~min}$ (Fig. 4B, gray bars). On the other hand, the wave amplitude of sperm remained high until $60 \mathrm{~min}$ of incubation when recombinant HSP70 was included in the incubation mixture (Fig. 4B, solid bars). The representative waveform of the flagella after $30 \mathrm{~min}$ of incubation in the presence or absence of recombinant HSP70 is shown in Fig. $4 \mathrm{C}$ and D. As shown in the figure, the flagellar movements of the sperm were weak and vigorous in the absence and presence of recombinant HSP70 respectively. Moreover, the average maximum intensity of Fluo-8H fluorescence, a fluorescent calcium indicator, increased significantly in the presence of recombinant HSP70 compared with that in the control sperm
(Fig. 5A). The fluorescent level in the tag protein group was comparable to that in the control sperm. In addition, the ATP content of cells during incubation was higher in the presence of HSP70 than that in the control sperm (Fig. 5B). Taken together, these results indicate that HSP70 maintains vigorous sperm motility in vitro.

\section{Binding of HSP7O to the sperm surface}

To understand how HSP70 affects sperm motility, we investigated whether recombinant HSP70 can interact with sperm. As a result, immunoreactive signals were clearly observed on the entire surface of the sperm (Fig. 6A and B). These signals were considered specific as no such signal was observed when the same preparations were incubated with anti-HSP70 antiserum preincubated with antigen proteins (Fig. 6C and D). To elucidate the nature of HSP70 binding to the sperm, we carried out far-western blotting. The SDS-PAGE results indicated that HSP70 did bind to the $\sim 35 \mathrm{kDa}$ protein of the SPML (Fig. 7A, lane +), indicating that HSP70 bound to the sperm by interacting with the $35 \mathrm{kDa}$ protein on the plasma membrane. By overlaying the chemiluminescent signal on the image of the PVDF membrane stained with CBB, we successfully identified the $35 \mathrm{kDa}$ immunoreactive band in the gel (Fig. 7, arrow in lane CBB). We then excised this band from the gel and carried out MS/MS analysis of the protein. Using the de novo sequencing software, PEAKS, the amino acid sequences detected by the MS/MS analysis were identified as being VDAC2 (Fig. 7B and Table 1). The coverage score of the sequences obtained from MS/MS data was $42 \%$, and two other software packages, Mascott and SPIDER, also found that the $35 \mathrm{kDa}$ protein was VDAC2 with high reliability (Table 1). These results demonstrated that the SPML protein that interacts with HSP70 is VDAC2.
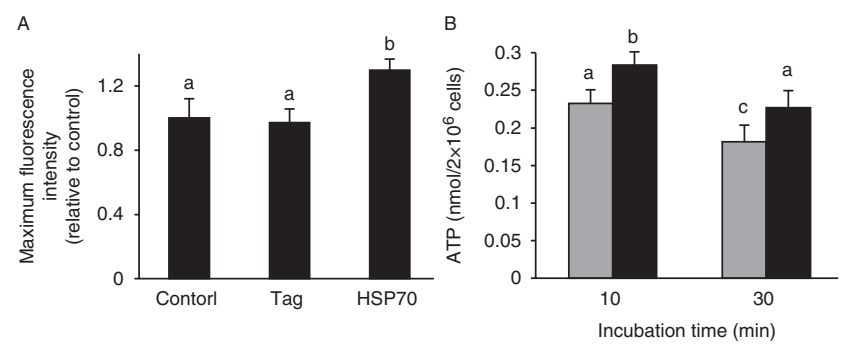

Figure 5 Effects of $\mathrm{HSP} 70$ on $\left[\mathrm{Ca}^{2+}\right]_{i}$ and $[\mathrm{ATP}]_{i}$ in sperm during incubation. (A) Maximum Fluo-8H fluorescent intensities of the flagellar region in the presence of HSP70 $(30 \mu \mathrm{g} / \mathrm{ml})$ or tag protein $(30 \mu \mathrm{g} / \mathrm{ml})$ are shown. Control sperm were incubated with a vehicle (PBS) alone. In the figure, the data are shown as a percentage of the mean of control values. Data are expressed as means \pm s.D. of six independent experiments with ten sperm. Values with different letters are significantly different $(P<0.01)$. (B) Intracellular ATP levels during incubation (10 or $30 \mathrm{~min}$ ) in the presence of tag protein (gray bars, $30 \mu \mathrm{g} / \mathrm{ml}$ ) or recombinant HSP70 (black bars, $30 \mu \mathrm{g} / \mathrm{ml}$ ). Data are expressed as means \pm s.D. of three independent experiments. Values with different letters are significantly different $(P<0.05)$. 

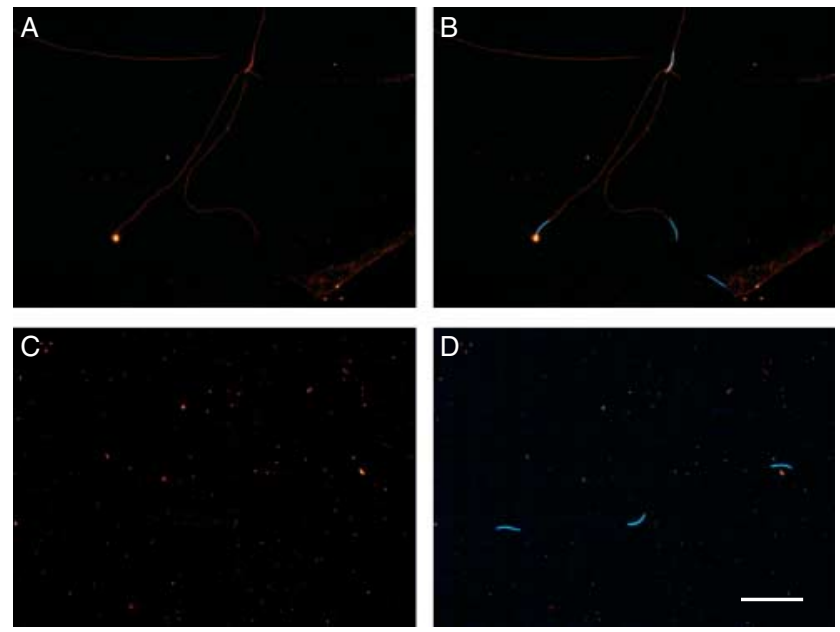

Figure 6 Binding of HSP70 to the sperm surface. Ejaculated sperm were incubated with $30 \mu \mathrm{g} / \mathrm{ml} \mathrm{HSP70}$ for $30 \mathrm{~min}$, fixed, smeared on a slide, and detected with anti-HSP70 antiserum (A and B; 1:300) or antiHSP70 antiserum preabsorbed with antigen proteins (C and D; 1:300). Sperm nuclei were counterstained with DAPI and merged with antiHSP70-reactive signals ( $B$ and D). Representative images of repeated experiments are shown. Bar $=50 \mu \mathrm{m}$.

To gain further support for the idea that VDAC2 is involved in the process of HSP70-mediated sperm activation, we incubated the ejaculated sperm with recombinant HSP70 in the presence or absence of erastin, a selective inhibitor of VDACs. As expected, both the linear velocity (Fig. 7C) and wave amplitude (Fig. 7D) potentiated by recombinant HSP70 returned to the control levels in the presence of erastin.

\section{Discussion}

In this study, we demonstrated that the highly conserved protein HSP70 can activate quail sperm and also that HSP70 maintains sperm motility for an extended period in vitro. Specifically, recombinant HSP70 potentiated sperm flagellar movements by increasing the wave amplitude, which was retained for at least $1 \mathrm{~h}$ of incubation. In addition, supplementation of recombinant HSP70 in the sperm extender increased both intracellular calcium and ATP concentrations during incubation. Finally, recombinant HSP70 was found to bind to the sperm surface. This is the first study to demonstrate that HSP70 affects sperm motility in an avian species. Whether HSP70 affects the beat frequency of the cilia lining the oviductal lumen is not known.

HSP70 is one of the most widespread molecular chaperone molecules and is central to the maintenance of cellular homeostasis in response to stressful cellular conditions (Duagaard et al. 2007). In general, intracellular localization of HSP70 within the cytosol and in organelles such as the nucleus, mitochondria, and endoplasmic reticulum has been reported as this protein lacks an $\mathrm{N}$-terminal signal sequence (Duagaard et al. 2007). However, Lancaster \& Febbraio (2005) have recently reported the presence of exosome-mediated release of HSP70 in human peripheral blood mononuclear cells under both basal and heat-stressed conditions. However, this process of protein export differs markedly from the conventional protein secretory pathways because brefeldin A, a classical inhibitor of membrane trafficking pathways in cells, does not interfere with the release of the exosomes (Lancaster \& Febbraio 2005). While it is not known whether the surface epithelium of the UVJ mucosa releases exosomes containing HSP70 into the lumen, ultrastructural analysis of turkey SSTs has revealed the existence of small vesicular components in the lumen (Schuppin et al. 1984). In HeLa cells, the overexpression of HSP70 has been reported to result in the downregulation of oxidative phosphorylation in mitochondria; consequently, continuous upregulation of glycolysis compensates for any fluctuations in intracellular ATP levels (Wang et al. 2012). The ATP that is responsible for flagellar movements in mouse sperm is mainly produced by glycolysis (Mukai \& Okuno 2004). Similarly, data from our preliminary experiments indicated that glycolysis may play a key role in the provision of ATP for flagellum mobility in Japanese quail. Our data indicated that deoxyglucose, an inhibitor of glycolysis, strongly blocked sperm motility (data not shown). Based on these findings, it is possible that the enhancement of glycolysis by HSP70 in the sperm could possibly explain the activation of sperm motility observed in the present study. On the other hand, Froman et al. have reported that rooster sperm motility is dependent on mitochondrial calcium cycling in the presence of extracellular sodium because sperm are rendered immotile by depletion of the extracellular $\mathrm{Na}^{+}$or by the treatment of CGP 37157, an inhibitor of the mitochondrial $\mathrm{Na}^{+}$/ $\mathrm{Ca}^{2+}$ exchanger, in the presence of $\mathrm{Ca}^{2+}$ (Froman \& Feltmann 2005). Since the mitochondrial $\mathrm{Ca}^{2+}$ cycle constitutes a control point for mitochondrial ATP production, these observations indicate that fowl sperm obtain energy for flagellar movement, in part, from mitochondria. The additional proteome analysis carried out by the same group indicated that glycolytic enzymes and related proteins such as glucose transporter 3, lactate dehydrogenase, and phosphoglucokinase 1 are more abundant in the high-sperm mobility line than in the low-sperm motility line (Froman et al. 2011). We currently do not know the contribution of mitochondrial respiration as an energy source to sperm motility in Japanese quail. However, an increase in intracellular $\mathrm{Ca}^{2+}$ levels appears to be important for maintaining sperm motility. This assumption is supported by the finding in chickens that sperm cell $\mathrm{Ca}^{2+}$ content is significantly greater in the high-sperm mobility line than in the low-sperm mobility line (Froman et al. 2011). Further experiments will be needed to uncover the mechanism as to how HSP70 activates sperm motility. In addition, we are currently focusing on the isolation and 
A

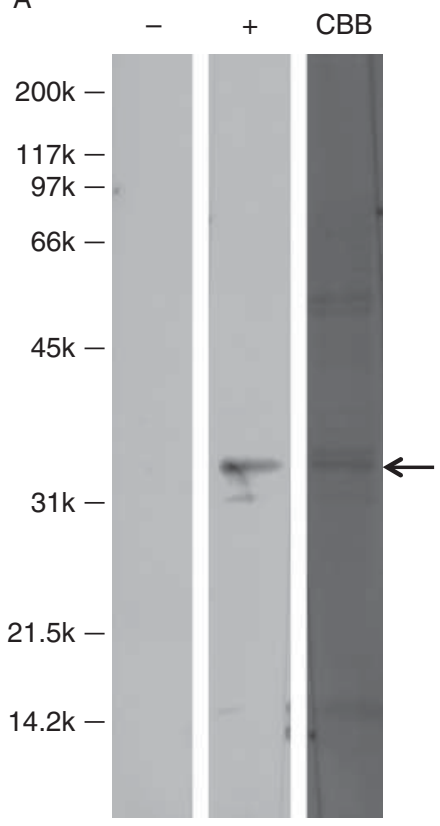

B

1 AIPPSYADLG KSARDIFNKG YGFGLVKLDV KTKSASGVEF TTSGSSNTDT 51 GKVNGSLETK YKWAEYGLTF TEKWNTDNTL GTEIAIEDQI AKGLKLTFDT 101 TFSPNTGKKS GKIKSAYKRE CLNLGCDVDF DFAGPAIHGS AVFGYEGWLA 151 GYOMTFDSAK SKLTRNNFSV GYKTGDFOLH TNVNDGSEFG GSIYOKVSDN 201 LETAVNLAWT AGSNSTRFGI AAKYKLDSTA SISAKVNNSS LVGVGYTQTL 251 RPGVKLTLSA LIDGKSINAG GHKLGLGLEL EA
C

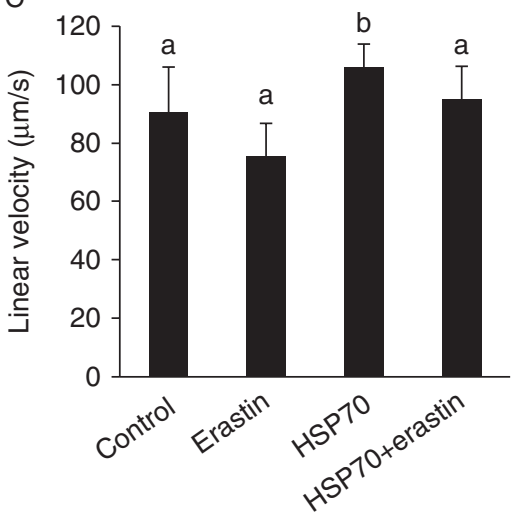

D

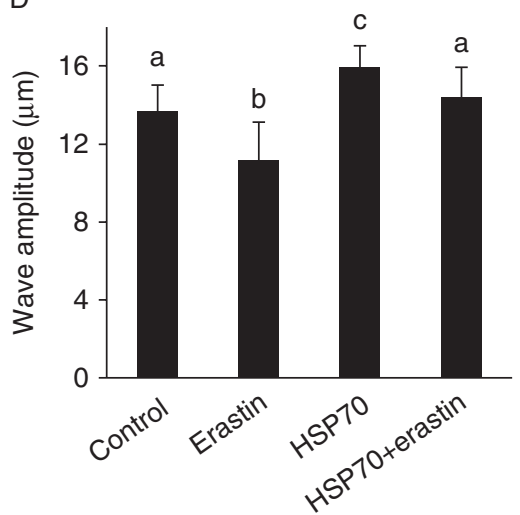

Figure 7 Identification of the binding partner of HSP70 in the sperm. (A) Sperm membrane ( $5 \mu \mathrm{g} / \mathrm{lane}$ ) was separated by SDS-PAGE and electrotransferred onto a PVDF strip. One strip was subjected to CBB staining. Intact strips were blocked with N101 and incubated with (+) or without (-) HSP70 $(0.1 \mu \mathrm{g} / \mathrm{ml})$. Washed strips were blocked again with the same blocker, incubated with anti-HSP70 antiserum (1:1000), and then incubated with a HRP-labeled secondary antibody (1:10 000). The $35 \mathrm{kDa}$ band in the sperm membrane specifically binds to HSP70. (B) The deduced amino acid sequence of voltage-dependent anion selective channel protein 2 (GenBank accession number: P82013). Peptide fragments detected by MS/MS analysis are shown in bold. (C and D) Linear velocity of sperm (C) and maximum amplitude of flagellar bending (D) at 30 min of incubation in the presence of recombinant HSP70 $(30 \mu \mathrm{g} / \mathrm{ml})$, erastin $(10 \mu \mathrm{M})$ or both was measured. The control sperm were incubated in the medium supplemented with vehicle alone. Data are expressed as means \pm s.D. of three independent experiments with ten sperm. Values with different letters are significantly different $(P<0.05)$.

analysis of exosomes from the oviduct to determine the specific roles of the putative HSP70-containing exosomes in sperm migration within the oviduct.

Given that the vagina and UVJ are in a spiral configuration bound by thick layers of connective tissue, it is not possible to make direct observations of sperm entering and exiting the SSTs. After natural mating, the ejaculated sperm are deposited into the vagina. However, it has been reported that in turkeys, more than $80 \%$ of the sperm are rejected from the vagina soon after mating (Howarth 1971). In addition, $<1 \%$ of the sperm that are inseminated into the vagina enter the SSTs (Bakst et al. 1994). To determine sperm migration in oviducts, Das et al. studied the rate of SST filling after a single insemination event in chickens. Sperm artificially introduced into the vagina of a chicken reached the SSTs within an hour and the rate of SST filling tended to increase until $24 \mathrm{~h}$ after insemination (Das et al. 2006).

Table 1 Summary of the results of the MS/MS analysis of the binding of HSP70 protein to sperm surface in Japanese quail ${ }^{\text {. }}$.

\begin{tabular}{|c|c|c|c|c|c|c|c|}
\hline $\begin{array}{l}\text { Amino } \\
\text { acid no. }\end{array}$ & Sequence & $\begin{array}{c}\text { Observed } \\
(\mathrm{m} / \mathrm{z})\end{array}$ & Charge & Mr (Calc) & $\begin{array}{c}\text { PEAKS } \\
\text { (score \%) }\end{array}$ & $\begin{array}{c}\text { SPIDER } \\
\text { (score no.) }\end{array}$ & $\begin{array}{c}\text { MASCOT } \\
\text { (score) }\end{array}$ \\
\hline $20-27$ & GYGFGLVK & 420.7515 & $2+$ & 839.4541 & 98.3 & 31.1 & 56.2 \\
\hline $34-52$ & SASGVEFTTSGSSNTDTGK & 916.9418 & $2+$ & 1831.8074 & 99.2 & 71.6 & 141.3 \\
\hline $63-73$ & WAEYGLTFTEK & 672.8547 & $2+$ & 1343.6396 & 99.2 & 44.1 & 74.6 \\
\hline $74-92$ & WNTDNTLGTEIAIEDQIAK & 1066.572 & $2+$ & 2131.0432 & 99.2 & 67.9 & 147.7 \\
\hline $74-92$ & WNTDNTLGTEIAIEDQIAK & 711.3925 & $3+$ & 2131.0432 & 99.2 & 67.9 & 75.7 \\
\hline $96-108$ & LTFDTTFSPNTGK & 714.889 & $2+$ & 1427.6934 & 99.2 & 46.9 & 66.1 \\
\hline 96-109 & LTFDTTFSPNTGKK & 519.6307 & $3+$ & 1555.7883 & 99.2 & 51.3 & 69.3 \\
\hline $166-173$ & NNFSVGYK & 464.7489 & $2+$ & 927.445 & 93.3 & 30.4 & 31.3 \\
\hline 174-196 & TGDFQLHTNVNDGSEFGGSIYQK & 838.7631 & $3+$ & 2513.1458 & 99.2 & 46.0 & 103.7 \\
\hline $256-265$ & LTLSALIDGK & 515.832 & $2+$ & 1029.6069 & 90.3 & 29.2 & 31.2 \\
\hline $274-282$ & LGLGLELEA & 914.554 & $1+$ & 913.512 & 45.0 & - & 16.7 \\
\hline
\end{tabular}

${ }^{\mathrm{a} A l l}$ peaks are monoisotopic. 
Although the mechanisms underlying the process of sperm selection are not known, the intrinsic mobility of sperm may be an important factor in the adovarian transport of sperm in the vagina and the uptake of sperm by the SSTs (Froman 2003). Bakst (2011) speculated in his review that not only intrinsic sperm motility but also a fluid transport mechanism in the vagina might be responsible for rapid sperm transport to the UVJ. He also found that the luminal $\mathrm{pH}$ of the mid-vagina of hens rose to 7.51 from 7.15 within 20 min of oviposition and speculated that this variation in environmental $\mathrm{pH}$ could impact sperm motility $8-12 \mathrm{~h}$ post-oviposition (Bakst 1980).

In the present study, the intravaginal injection of antiHSP70 antibody dramatically decreased the fertility of birds, indicating the physiological importance of HSP70 in sperm migration in the oviduct. We expected the injected IgG to reach the UVJ, because in our preliminary experiment in which Hoechst 33342 DNA dye was injected into the vagina using the same protocol, IgG injection was able to stain the nucleus of the surface epithelium of the UVJ (data not shown). Based on the expression pattern of $H S P 7 O$ mRNA in the UVJ, it can be suggested that the luminal abundance of HSP70 might peak around 20-25 h after oviposition and the injected antibody could efficiently neutralize this protein released from the surface epithelium of the UVJ. However, the rate of SST filling in hens that were intravaginally injected with anti-HSP70 antibody did not differ from that in the control hens. Considering these reports and our current observations, it can be suggested that HSP70 does not affect sperm movement during passage in the vagina, which is linked to sperm uptake by the SSTs.

Our results demonstrated that $H S P 70$ mRNA is highly expressed in the infundibulum and in the UVJ, which is the site of sperm storage in the avian oviduct. In addition, we found that $H S P 7 O$ mRNA is also actively transcribed in the vagina, which is thought to be the site of sperm selection in birds (Howarth 1971). We observed that the expression of HSP70 in the UVJ increases before oviposition, indicating that the expression of HSP70 may be regulated during the ovulatory cycle. It is considered that the observed HSP70 expression pattern would facilitate fertilization as, based on the findings of our previous study in which we demonstrated that sperm release from the SSTs occurs $\sim 20 \mathrm{~h}$ after oviposition, the free swimming sperm would move up the oviduct after being released from the SSTs (Ito et al. 2011). The sperm released from the SSTs would probably be exposed to HSP70 in the lumen of the oviduct, activating sperm migration toward the infundibulum, which is the site of fertilization. This assumption is also supported by our findings, as both HSP7O mRNA and HSP70 protein were strongly expressed in the surface epithelium of the UVJ where the sperm were initially released from the SSTs. In our previous study, we found that sperm released from the SSTs are regulated under the stimulation of progesterone (Ito et al. 2011). Although we did not confirm the hypothesis that progesterone stimulates the expression and release of HSP70 from the surface epithelium of the UVJ, it is reasonable to suppose that progesterone stimulates not only sperm release from the SSTs, but also enhances HSP70 expression in the UVJ to facilitate fertilization in birds.

More importantly, we found that recombinant HSP70 specifically binds to the entire sperm surface by interacting with VDAC2. VDAC2 was originally characterized as a mitochondrial porin; however, $31 \mathrm{kDa}$ VDAC2 proteins have also been enriched from the plasma membrane fraction of human B lymphocytes (Pinto et al. 2010, Sabirov \& Merzlyak 2012). Based on a recent proteomic study on human mesenchymal stromal cell surfaces, the presence of VDAC2 in the plasma membrane has also been suggested (Niehage et al. 2011). In addition, VDAC2 has recently been found in the acrosomal or plasma membrane of human spermatozoa (Liu et al. 2011). These authors suggested that the plasmalemmal VDAC is involved in the induction of acrosome reaction through the mediation of $\mathrm{Ca}^{2+}$ transport; specifically, they showed how an ionophore A23187-induced increase in intracellular $\mathrm{Ca}^{2+}$ levels is inhibited in the presence of antibody against VDAC2 (Liu et al. 2011). Although we do not currently know how HSP70 modulates VDAC2 functions by binding or what form of intracellular signaling potentiates sperm motility, we did find that intracellular $\mathrm{Ca}^{2+}$ levels significantly increased in the presence of recombinant HSP70. The identification of the specific mechanism of how cellsurface VADC modulates sperm motility remains to be elucidated in the future.

In conclusion, in the present study, we demonstrated that the highly conserved protein HSP70 activates sperm motility in vitro. Analysis of the expression of HSP70 revealed that $H S P 70$ mRNA and HSP70 protein are expressed in the UVJ, where the protein is primarily localized in the surface epithelium. An increase in the expression level of HSP70 in the UVJ before oviposition indicates that the expression of HSP70 is hormonally regulated during the ovulatory cycle. Moreover, HSP70 was detected to bind to the entire sperm surface and the binding partner of HSP70 was found to be VDAC2. Since the timing of sperm release from the SSTs temporally coincides with a peak in HSP70 expression, it is possible that HSP70 activates sperm in the lumen of the UVJ, facilitating sperm migration toward the infundibulum, the site of fertilization in birds. The findings reported herein may clarify the role of oviducts in sperm migration from the SSTs to the infundibulum in birds.

\section{Declaration of interest}

The authors declare that there is no conflict of interest that could be perceived as prejudicing the impartiality of the research reported. 


\section{Funding}

This work was supported by financial support from a grantin-aid for scientific research (B; General) (24380153 to T Sasanami), a grant-in-aid for scientific research on innovative areas (24112710 to T Sasanami), and Japanese Association for Marine Biology (JAMBIO) (numbers 24-64 and 25-57 to T Sasanami).

\section{Acknowledgements}

The authors are grateful to Ms R Hamano for her technical assistance.

\section{References}

Bakst MR 1980 Chicken and turkey oviductal pH at known times postoviposition. Poultry Science 59 2793-2796. (doi:10.3382/ps. 0592793)

Bakst MR 1981 Sperm recovery from oviducts of turkeys at known intervals after insemination and oviposition. Journal of Reproduction and Fertility 62 159-164. (doi:10.1530/jrf.0.0620159)

Bakst MR 2011 Role of the oviduct in maintaining sustained fertility in hens. Journal of Animal Science 89 1323-1329. (doi:10.2527/jas.2010-3663)

Bakst MR, Wishart G \& Brullard JP 1994 Oviductal sperm selection, transport, and storage in poultry. Poultry Science Reviews 5 117-143.

Birkhead TR \& M Mller AP 1993 Sexual selection and the temporal separation of reproductive events: sperm storage data from reptile, birds and mammals. Biological Journal of the Linnean Society 50 295-311. (doi:10.1111/j.1095-8312.1993.tb00933.x)

Bobr LW, Ogasawara FX \& Lorenz FW 1964 Distribution of spermatozoa in the oviduct and fertility in domestic birds II. Transport of spermatozoa in the fowl oviduct. Journal of Reproduction and Fertility 8 49-58. (doi:10.1530/jrf.0.0080049)

Brillard JP 1993 Sperm storage and transport following natural mating and artificial insemination. Poultry Science 72 923-928. (doi:10.3382/ ps.0720923)

Burke WH \& Ogasawara FX 1969 Presence of spermatozoa in uterovaginal fluids of the hen at various stages of the ovulatory cycle. Poultry Science 48 408-413. (doi:10.3382/ps.0480408)

Compton MM, VanKrey HP \& Siegel PB 1978 The filling and emptying of the uterovaginal sperm-host glands in the domestic hen. Poultry Science 57 1696-1700. (doi:10.3382/ps.0571696)

Das SC, Isobe N, Nishibori M \& Yoshimura Y 2006 Expression of transforming growth factor- $\beta$ isoforms and their receptors in uterovaginal junction of the hen oviduct in presence or absence of resident sperm with reference to sperm storage. Reproduction 132 781-790. (doi:10.1530/rep.1.01177)

Duagaard M, Mikkel R \& Jaattela M 2007 The heat shock protein 70 family: highly homologous proteins with overlapping and distinct functions. FEBS Letters 581 3702-3710. (doi:10.1016/j.febslet.2007.05.039)

Elliott RM, Lloyd RE, Faseli A, Sostaric E, Georgiou AS, Satake N, Watson PF \& Holt WV 2009 Effects of HSPA8, an evolutionarily conserved oviductal protein, on boar and bull spermatozoa. Reproduction 137 191-203. (doi:10.1530/REP-08-0298)

Etches RJ \& Schoch JP 1984 A mathematical representation of the ovulatory cycle of the domestic hen. British Poultry Science 25 65-76. (doi:10.1080/13632758408454843)

Frie $\boldsymbol{\beta}$ AE, Sinowatz F \& Wrobel KH 1978 The uterovaginal sperm host glands of the quail (Coturnix coturnix japonica). Cell and Tissue Research 191 101-114.

Froman DP 2003 Deduction of a model for sperm storage in the oviduct of the domestic fowl (Gallus domesticus). Biology of Reproduction 69 248-253. (doi:10.1095/biolreprod.102.013482)

Froman DP \& Feltmann AJ 2005 Fowl (Gallus domesticus) sperm motility depends upon mitochondrial calcium cycling driven by extracellular sodium. Biology of Reproduction 72 97-101. (doi:10.1095/biolreprod. 104.033209)
Froman DP, Feltmann AJ, Pendarvis K, Cooksey AM, Burgess SC \& Rhoads DD 2011 A proteome-based model for sperm mobility phenotype. Journal of Animal Science 89 1330-1337. (doi:10.2527/ jas.2010-3367)

Holt WV 2011 Mechanism of sperm storage in the female reproductive tract: an interspecies comparison. Reproduction in Domestic Animals 46 68-74. (doi:10.1111/j.1439-0531.2011.01862.x)

Holt WV \& Lloyd RE 2010 Sperm storage in the vertebrate female reproductive tract: how does it work so well? Theriogenology $\mathbf{7 3}$ 713-722. (doi:10.1016/j.theriogenology.2009.07.002)

Howarth B 1971 Transport of spermatozoa in the reproductive tract of turkey hens. Poultry Science 50 84-89. (doi:10.3382/ps.0500084)

Ito T, Yoshizaki N, Tokumoto T, Ono H, Yoshimura T, Tsukada A, Kansaku N \& Sasanami T 2011 Progesterone is a sperm-releasing factor from the sperm-storage tubules in birds. Endocrinology 152 3952-3962. (doi:10.1210/en.2011-0237)

Kuehnel S \& Kupfer A 2012 Sperm storage in caecilian amphibians. Frontiers in Zoology 9 12. (doi:10.1186/1742-9994-9-12)

Kuroki M \& Mori M 1997 Binding of spermatozoa to the perivitelline layer in the presence of a protease inhibitor. Poultry Science $\mathbf{7 6} 748-752$.

Laemmli UK 1970 Cleavage of structural proteins during the assembly of the head of bacteriophage T4. Nature 227 680-685. (doi:10.1038/ 227680a0)

Lancaster GI \& Febbraio MA 2005 Exosome-dependent trafficking of HSP70. Journal of Biological Chemistry 280 23349-23355. (doi:10.1074/jbc.M502017200)

Liu B, Wanf P, Wang Z \& Zhang W 2011 The use of anti-VDAC2 antibody for the combined assessment of human sperm acrosome integrity and ionophore A23187-induced acrosome reaction. PLOS ONE 6 e16985. (doi:10.1371/journal.pone.0016985)

Ma B, Zhang K, Hendrie C, Liang C, Li M, Doherty-Kirby A \& Lajoie G 2003 PEAKS: powerful software for peptide de novo sequencing by MS/MS. Rapid Communications in Mass Spectrometry 17 2337-2342. (doi:10.1002/rcm.1196)

Matsudaira P 1987 Sequence from picomole quantities of proteins electroblotted onto polyvinylidene difluoride membranes. Journal of Biological Chemistry 262 10035-10038.

Mizuno K, Shiba K, Okai M, Takahashi Y, Shitaka Y, Oiwa K, Tanokura M \& Inaba K 2012 Calaxin drives sperm chemotaxis by $\mathrm{Ca}^{2+}$-mediated direct modulation of a dynein motor. PNAS 109 20497-20502. (doi:10.1073/ pnas.1217018109)

Mukai C \& Okuno M 2004 Glycolysis plays a major role for adenosine triphosphate supplementation in mouse sperm flagellar movement. Biology of Reproduction 71 540-547. (doi:10.1095/biolreprod.103. 026054)

Niehage C, Steenblock C, Pursche T, Bornhauser M, Corbeil D \& Hoflack B 2011 The cell surface proteome of human mesenchymal stromal cells. PLoS ONE 6 e20399. (doi:10.1371/journal.pone.0020399)

Perkins DN, Pappin DJC, Creasy DM \& Cottrell JS 1999 Probability-based protein identification by searching sequence databases using mass spectrometry data. Electrophoresis 20 3551-3567. (doi:10.1002/(SICl) 1522-2683(19991201)20:18<3551::AID-ELPS3551>3.0.CO;2-2)

Pinto VD, Messina A, Lane D \& Lawen A 2010 Voltage-dependent anion-selective channel (VDAC) in the plasma membrane. FEBS Letters 584 1793-1799. (doi:10.1016/j.febslet.2010.02.049)

Roy VK \& Krishna A 2010 Evidence of androgen-dependent sperm storage in female reproductive tract of Scotophilus heathi. General and Comparative Endocrinology 165 120-126. (doi:10.1016/j.ygcen.2009. 06.012)

Sabirov RZ \& Merzlyak PG 2012 Plasmalemmal VDAC controversies and maxi-anion channel puzzle. Biochimica et Biophysica Acta 1818 1570-1580. (doi:10.1016/j.bbamem.2011.09.024)

Sasanami T, Pan J, Doi Y, Hisada M, Kohsaka T \& Toriyama M 2002 Secretion of egg envelope protein ZPC after C-terminal proteolytic processing in quail granulosa cells. European Journal of Biochemistry 269 2223-2231. (doi:10.1046/j.1432-1033.2002.02880.x)

Satake N, Elliott RM, Watson PF \& Holt WV 2006 Sperm selection and competition in pigs may be mediated by the differential motility activation and suppression of sperm subpopulations within the oviduct. Journal of Experimental Biology 209 1560-1572. (doi:10.1242/ jeb.02136) 
Schuppin GT, VanKrey HP \& Denbow DM 1984 Ultrastructural analysis of uterovaginal sperm storage glands in fertile and infertile turkey breeder hens. Poultry Science 63 1872-1882. (doi:10.3382/ps.0631872)

Shindler H, Ben-David E, Hurwitz S \& Kempenich O 1967 The relation of spermatozoa to the glandular tissue in the storage sites of the hen oviduct. Poultry Science 46 1462-1471. (doi:10.3382/ps.0461462)

Simamura E, Shimada H, Hatta T \& Hirai K 2008 Mitochondrial voltagedependent anion channels (VDACs) as novel pharmacological targets for anti-cancer agents. Journal of Bioenergetics and Biomembranes 40 231-237. (doi:10.1007/s10863-008-9158-6)

Suarez SS 2010 How do sperm get to the egg? Bioengineering expertise needed! Experimental Mechanics 50 1267-1274. (doi:10.1007/s11340009-9312-z)

Wang L, Schumann U, Liu Y, Prokopchuk O \& Steinacker JM 2012 Heat shock protein 70 (Hsp 70) inhibits oxidative phosphorylation and compensates ATP balance through enhanced glycolytic activity. Journal of Applied Physiology 113 1669-1676. (doi:10.1152/japplphysiol.00658.2012)

Wheeler NC \& Andrews FN 1943 The influence of season on semen production in the domestic fowl. Poultry Science 22 361-367. (doi:10.3382/ps.0220361)
Wolfner MF 2011 Precious essences: female secretions promote sperm storage in Drosophila. PLoS Biology 9 e1001191. (doi:10.1371/journal. pbio.1001191)

Yagoda N, Rechenberg M, Zaganjor E, Bauer AJ, Yang WS, Fridman DJ, Wolpaw AJ, Smukste I, Peltier JM, Boniface JJ et al. 2007 RAS-RAFMEK-dependent oxidative cell death involving voltage-dependent anion channels. Nature 447 864-868. (doi:10.1038/nature05859)

Yoshimura T, Suzuki Y, Makino E, Suzuki T, Kuroiwa A, Matsuda Y, Namikawa T \& Ebihara S 2000 Molecular analysis of avian circadian clock genes. Molecular Brain Research 78 207-215. (doi:10.1016/ S0169-328X(00)00091-7)

Received 10 September 2013

First decision 30 September 2013

Revised manuscript received 27 October 2013

Accepted 5 November 2013 